\title{
Circulation pattern controls of wet days and dry days in Free State, South Africa
}

\author{
Chibuike Chiedozie Ibebuchi ${ }^{1}$ (D)
}

Received: 14 March 2021 / Accepted: 12 July 2021 / Published online: 24 July 2021

(c) The Author(s) 2021

\begin{abstract}
Atmospheric circulation is a vital process in the transport of heat, moisture, and pollutants around the globe. The variability of rainfall depends to some extent on the atmospheric circulation. This paper investigates synoptic situations in southern Africa that can be associated with wet days and dry days in Free State, South Africa, in addition to the underlying dynamics. Principal component analysis was applied to the T-mode matrix (variable is time series and observation is grid points at which the field was observed) of daily mean sea level pressure field from 1979 to 2018 in classifying the circulation patterns in southern Africa. 18 circulation types (CTs) were classified in the study region. From the linkage of the CTs to the observed rainfall data, from 11 stations in Free State, it was found that dominant austral winter and late austral autumn CTs have a higher probability of being associated with dry days in Free State. Dominant austral summer and late austral spring CTs were found to have a higher probability of being associated with wet days in Free State. Cyclonic/anti-cyclonic activity over the southwest Indian Ocean, explained to a good extent, the inter-seasonal variability of rainfall in Free State. The synoptic state associated with a stronger anti-cyclonic circulation at the western branch of the South Indian Ocean high-pressure, during austral summer, leading to enhanced low-level moisture transport by southeast winds was found to have the highest probability of being associated with above-average rainfall in most regions in Free State. On the other hand, the synoptic state associated with enhanced transport of cold dry air, by the extratropical westerlies, was found to have the highest probability of being associated with (winter) dryness in Free State.
\end{abstract}

\section{Introduction}

Parts of southern Africa have already started experiencing extreme conditions (e.g. drought) (Sousa et al. 2018; Archer et al. 2019), and drought conditions are expected to increase in southern Africa under greenhouse-induced climate change (IPCC 2013). The hydroclimate of South Africa which is located at the subtropical high-pressure cell is relatively more vulnerable to a changing climate making it necessary for enhanced predictability of extremes in the region, in addition to understanding the underlying mechanism associated with extreme events at specific regions. Free State is centrally located in South Africa, and its economy is largely dependent on maize agriculture. According to

Responsible Editor: J.-F. Miao.

Chibuike Chiedozie Ibebuchi

chibuike.ibebuchi@uni-wuerzburg.de

1 Institute of Geography and Geology, University of Würzburg, Am Hubland, 97074 Würzburg, Germany
Zuma-Netshiukhwi et al. (2013), most farmers in parts of the Free State are unfamiliar with the application of weather forecasts and still depend on their experience and traditional knowledge for farming decision-making. Thus there is the need for studies that extend the predictability of rainfall in Free State, which can also be of benefit to water decisionmakers. This paper examines how specific synoptic situations in southern Africa can be used to forecast the probability of wet and dry events in the Free State.

The concept of synoptic climatology deals with the connection between large-scale atmospheric circulations and local surface variables. It involves the classification of the circulation patterns in a region, and the linkage of the classified patterns to the variability of surface variables in a local region, for example in Andorra (Esteban et al. 2005), in the whole Pyrenees (Lemus-Canovas et al. 2019); in Austria (Seibert et al. 2007) among many others. When used to explain surface variables, classification of circulation patterns can be considered as a method of statistical downscaling (Maraun and Widmann 2018), which involves the correlation of clustered days with a similar 
spatial pattern, to a large-scale atmospheric variable. Linking atmospheric circulation to local surface variables in the Mediterranean region, Maheras and Kolyva-Machera (1990) noted that zonal circulation patterns are associated with dry periods whereas meridional circulation patterns are associated with humid periods.

Austral summer rainfall variability in southern Africa is influenced by a low level (at about $850 \mathrm{hPa}$ ) land-based convergence zone (Tyson 1986; Cook 2000; Ninomiya 2008; Lazenby et al. 2016), called the South Indian Ocean Convergence Zone (SICZ). The SICZ which extends off the southeast coast of southern Africa is the major largescale feature that modulates the hydroclimate of southern Africa.

Relaxation of trade winds during the austral warm seasons, at the region of the Angola warm current, lead to the development of a warm pool in the region (Reason and Smart 2015). Moisture flux from the warm pool feeds into the Angola low, which is a tropical low during austral summer associated with moist convection (Munday and Washington 2017). During austral summer, moisture from the cross-equatorial northeast trade wind also feeds into the Angola low. The cyclonic circulation associated with the Angola low transports moisture from the warm pool and the tropical Indian Ocean to the (eastern) subtropical regions of southern Africa. According to Vigaud et al. (2009), the Inter-tropical Convergence Zone (ITCZ) modulates the SICZ through the Angola low - the sustenance of the Angola low can be related to the enhancement of the ITCZ. The anti-cyclonic circulation at the South Indian Ocean's highpressure strengthens southeast winds, and thus enhances moisture advection into southern Africa from the southwest Indian Ocean. Low-level convergence of the moisture from the southwest Indian Ocean advected by easterly winds and the moisture advected from the tropical South Atlantic Ocean (warm pool) by the circulation at the Angola low, create the foundation zone of the SICZ (Cook 2000). According to Cook (2000) the Agulhas current equally influences the SICZ through the enhanced evaporation in the region. Additionally, rainfall variability in South Africa is also modulated by sea surface temperature (SST) anomalies in the Agulhas current (Walker 1990).

Sylla et al. (2011) noted that diabatic heating and moisture convergence are two phenomena that lead to deep conditional instability, which enhances convective rainfall. Enhanced diabatic heating, leads to the formation of a thermal tower (typically in the western regions of southern Africa), known as the continental tropical low. The continental tropical low is associated with enhanced vertical velocity and convective instability. Thus in the presence of adequate moisture at the boundary layer, its occurrence normally correlates with enhanced rainfall in southern Africa. Cook (2000) noted that the variability in the strength and position of the South Indian Ocean high pressure and continental heating are the major factors that affect the position and strength of the SICZ.

During austral winter (JJA) the northward track of the mid-latitude cyclones allows cold fronts to sweep across the regions in South Africa with the Mediterranean climate leading to enhanced winter rainfall in the southwestern regions of South Africa (e.g. Western Cape).

This paper uses the concept of obliquely rotated principal component analysis (PCA), applied to the T-mode matrix of a climatic variable that explains atmospheric circulation (Richman 1981; Martin-Vide et al. 2008), in obtaining the circulation types (CTs) in southern Africa. For the characterization of how the mechanism of the individual CTs could be related to rainfall in Free State, the concept of moisture flux convergence (Kuo 1965) at $850 \mathrm{hPa}$ will be incorporated in the analysis. Several researchers have found that the parameterization of convective rainfall could be well linked to the concept of moisture convergence (Sylla et al. 2011; Loriaux et al. 2017).

The focus of this paper is thus structured as follows:

1. Principal component analysis will be used as an eigenvector-based classification tool to obtain an ample set of CTs in southern Africa.

2. Physically motivated correlation between the mechanism of the CTs and rainfall variability in Free State will be investigated.

\section{Data and methodology}

Classification of CTs is achieved with gridded reanalysis mean sea level pressure (SLP) from the European Center for Medium-Range Weather Forecasts (ECMWF), ERA-Interim (Dee et al. 2011). Divergence and wind vector data sets at $850 \mathrm{hPa}$ are also obtained from ERA-Interim. The original temporal resolution of the data sets is $6 \mathrm{~h}$, from 1979 to 2018. Daily averages are computed, for the complete analysis period. The horizontal resolution of the ERA-Interim SLP dataset is $0.75^{\circ} \times 0.75^{\circ}$. The spatial coordinate for the circulation typing is $5.25^{\circ} \mathrm{E}-55.25^{\circ} \mathrm{E}$ and $6^{\circ} \mathrm{S}-50.25^{\circ} \mathrm{S}$. The adjacent oceans are included to capture moisture advection processes. Daily rainfall data from 11 stations in Free State, obtained from http://www.dwa.gov.za/Hydrology/ Verified/hymain.aspx, for the 1979-2018 period, are used in characterizing the rainfall characteristics of the CTs in Free State, South Africa (Fig. 1). The dotted red lines in Fig. 1 are the geographical locations of the selected rainfall stations in Free State. The selection of the stations is based on having complete daily rainfall estimates for the chosen analysis period (i.e. 1979-2018), which is long enough (greater than 
Fig. 1 The location of the local study region, Free State, in South Africa. The red dots are the location of the 11 selected rainfall stations in Free State

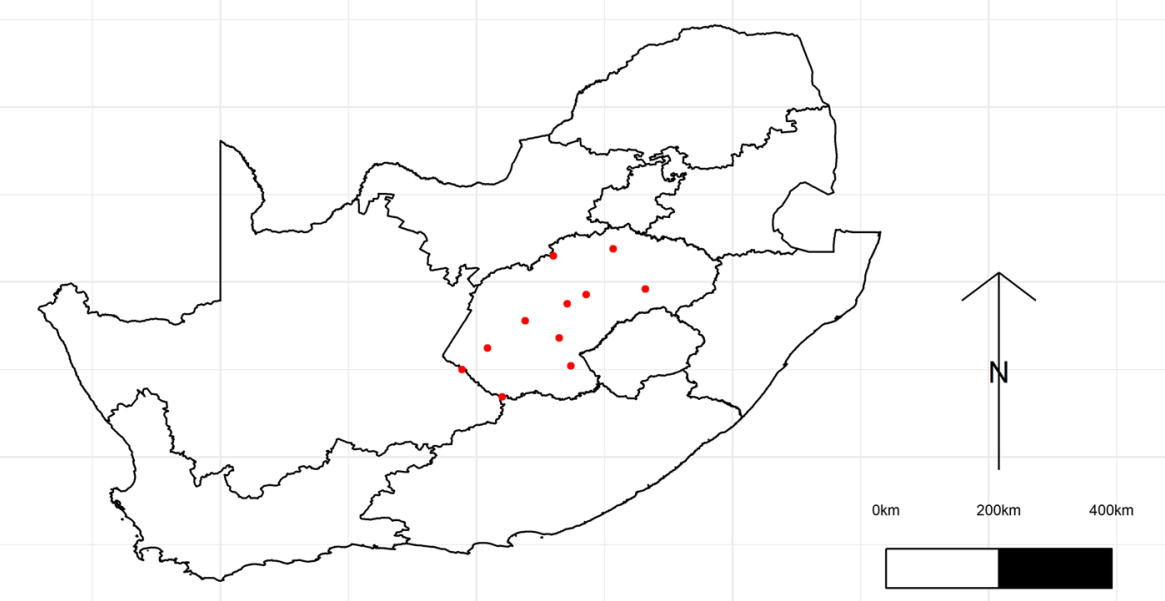

30 years) to capture the climatology of the patterns of atmospheric circulation in southern Africa.

For the classification of the CTs in southern Africa, obliquely rotated PCA is applied to the T-mode matrix of the daily z-score standardized SLP field. Kidson (1997) pointed out that SLP provides a good representation of synoptic-scale systems and explains the relationship between topography and low-level flow. He further noted that between 1000 and $500 \mathrm{hPa}$, the choice of the level to use in the classification has little influence on the explanation of surface variables. The decision to represent the matrix in a T-mode structure is based on the finding that obliquely rotated PCA on the T-mode matrix of a field that explains atmospheric circulation is an optimal technique for circulation typing (Richman 1986; Compagnucci and Richman 2008). Richman and Lamb (1985) noted that rotated PCA on the T-mode field results in a simplified time-series isolating subgroups of observations with a coherent spatial pattern. In the classification process, a correlation matrix is used, which yielded correlation coefficients between pairs of daily time observations in the study period. Singular value decomposition is used in factorizing the correlation matrix to obtain the PC scores, eigenvalues, and eigenvectors. The selection of the optimal number of components to retain is based first, on the scree-test (Cattell 1966; Wilks 2006). This was helpful to have an idea of the range of possible optimal number of components to retain for the analysisbased on cutting the component numbers after a relatively small slope is followed by a noticeable drop. The discarded components have typically low and close eigenvalues in line with the recommendation of North et al. (1982) on ensuring the separability of eigenvalues of the retained components. However, since the PCs are rotated in subsequent steps, the philosophy of North et al. (1982) might not be sufficient. Aslo, Preisendorfer et al. (1981) noted that a few of the discarded components might contain meaningful information necessary for the research goal. Thus, sensitivity analysis is also applied for the optimization of the number of components to retain. The sensitivity analysis ensures that after retaining typically components with separated eigenvalues that explain more of the variability in the data set, the addition of a further component uncovers a new pattern that has not been already delineated by previous vectors, and this is statistically approached by visual inspection of the maps, loadings, and ensuring that the congruence coefficient between the added input pattern (i.e. component score) and the already classified input patterns is low (Richman 1981). This also follows the argument of Harr and Elsberry (1995) in deciding the number of clusters to retain in a fuzzy circulation typing technique, that "the number of clusters is increased until the additional cluster either represents a subset of extreme cases from previously defined clusters or the number of members within the new cluster is less than $10 \%$ of the next smallest cluster".

Richman and Lamb (1985) recommended that multiplying the eigenvectors by the square root of their corresponding eigenvalues makes them more responsive to rotation. Hence the retained eigenvectors are further postmultiplied with the square root of their corresponding eigenvalues which makes them longer than a unit length henceforth referred to as loadings. To simplify the structure of the eigenvector loadings, they are rotated obliquely using Promax at a power of 2 (Richman 1986). The oblique rotation maximizes the number of near-zero loadings so that each retained component clusters a unique number of days that a general influence can be attributed to (Richman 1981). Also, the decision of using oblique rotation is to ensure that orthogonality constraint does not lead to artificial physical features in the classification (Richman 1981; Wilks 2006). The component scores present the input spatial patterns localized in time by the eigenvector loadings. Loadings (time-steps) that are near zero do not contribute to the PC sores (Compagnucci and Richman 2008). The absolute value of the loadings represent a vital 
signal, and for a given retained component, further clustering of the component loadings into negative high loadings and positive high loadings using a specified threshold will decrease the internal distances among classes so that there is greater similarity between days grouped under a given class (Richman and Gong 1999). Thus each component yields two classes and the SLP composite of the days grouped under a class is the circulation type (CT). Richman and Gong (1999) recommended that threshold values within the range of $0.2-0.35$ will be sufficient to separate the PCs; here \pm 0.2 is used. A detailed explanation of all the subjective decisions followed in the classification is explained in Ibebuchi (2021a).

For the linkage of the CTs, classified in this paper, to wet days (dry days) in Free State, wet days (dry days) clustered under each CT, are characterized as the count of days, per station, with daily rainfall amount greater than (less than) $0.3 \mathrm{~mm}$ (Brisson et al. 2011; Plavcova et al. 2013).

The rainfall characteristics of each $\mathrm{CT}$, concerning the probability of being associated with dry days and wet days, are calculated using Eqs. 1 and 2, respectively.

$$
\begin{gathered}
P_{\mathrm{d}_{i}}=\frac{d_{i}}{N_{i}} \times 100, i=1 \ldots n \\
P_{\mathrm{w}_{i}}=\frac{w_{i}}{N_{i}} \times 100, i=1 \ldots n
\end{gathered}
$$
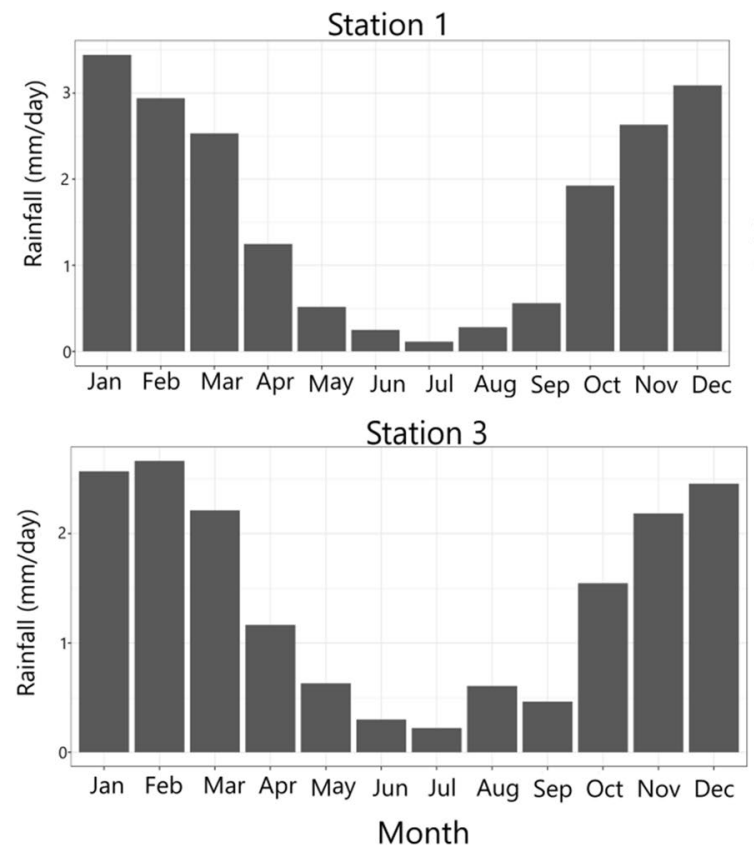

$P_{\mathrm{d}_{i}}$ is the percentage of dry days for a given CT; $d_{i}$ is the total number of dry days for the CT in question; $N_{i}$ is the total number of days clustered under a given CT. $P_{\mathrm{w}_{i}}$ is the percentage of wet days in a given CT, and $w_{i}$ is the total number of wet days for the CT in question and $n$ is the number of CTs classified.

Further analysis of the operational mechanism of the CTs associated with wet and dry conditions in Free State is made using moisture flux and divergence field at $850 \mathrm{hPa}$. The $850 \mathrm{hPa}$ height is chosen since it is the height above the eastern escarpment. Moisture flux is calculated as the product of specific humidity and wind speed.

\section{Study regions}

Southern Africa is located between three oceans - the Southern Ocean (south of South Africa), the South Atlantic Ocean, and the South Indian Ocean. The western subtropical regions of Southern Africa are relatively drier than the eastern regions due to the influence of the cold Benguela current. Rainfall is mostly in austral summer (DJF), except for the southwestern regions of South Africa that are characterized by the Mediterranean climate. The local study region, Free State, is a province in South Africa. Its altitude is about $1600 \mathrm{~m}$ above sea level. Figure 2 shows the annual cycle of rainfall, for four stations in Free State. Late austral autumn to early austral spring (May-October) is relatively the driest months, while late austral spring to early austral autumn (November-March) is relatively the wettest months.
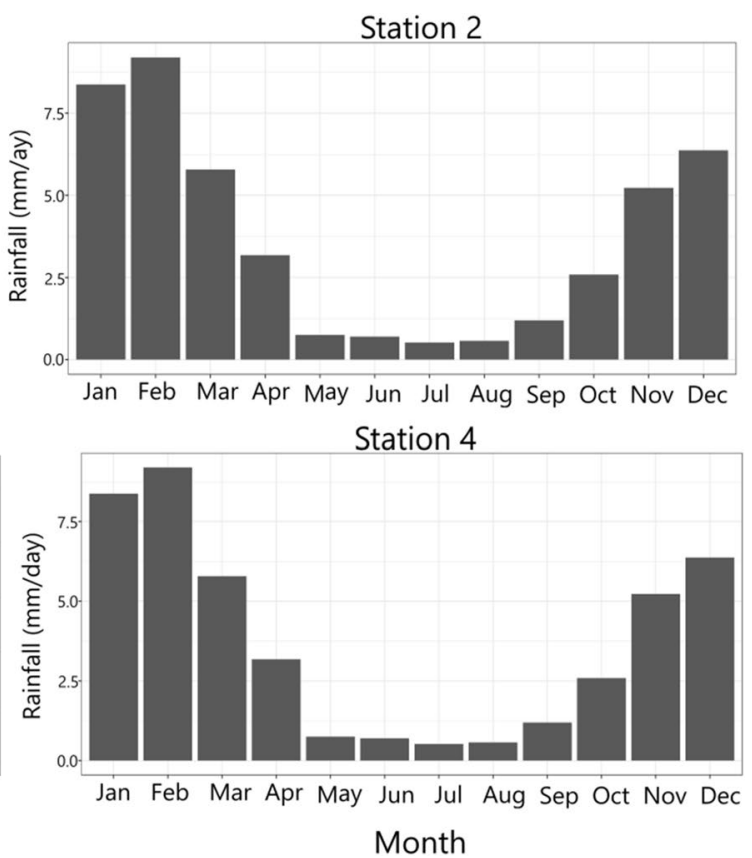

Fig. 2 Annual cycle of rainfall at four of the selected rainfall stations in Fig. 1 
Similar results were obtained for other stations in Fig. 1. Daily rainfall amounts are relatively highest during austral summer months (DJF). Generally, based on the Mann-Kendall test (Mann 1945; Kendall 1975) for linear trends, at a 95\% confidence level, the trend in wet days, dry days, and annual average rainfall in the selected stations are not statistically significant (not shown).

\section{Results}

\subsection{Circulation types in southern Africa}

By retaining 9 optimal components, 18 CTs were classified. Table 1 shows the explained variance for each of the retained components. Figure 3 shows the SLP composites (i.e. CTs) classified in the study region. Figure 4 shows the annual cycle for each CT in Fig. 3. In as much as it is common for the CTs to occur at any time of the year, the CTs can be further classified with respect to their dominance in either austral winter/autumn season or austral summer/ spring season. The dominant period of a given CT is also when its rain-bearing or rain-suppressing mechanism is most likely to be expressed. CT1, CT6, CT7, CT9, CT11, CT14, and CT16 can be grouped as winter/autumn CTs. CT9 and CT11 extend dominance into early austral spring (September/October). Generally, they can be analogous to CTs associated with cold seasons. Similarly, CT2, CT3, CT5, CT8, CT10, CT12, CT13, CT15, and CT18 can be grouped as austral summer/spring CTs. Their dominant periods are within the range of October (late austral spring) to February (late austral summer). CT5, CT2, and CT3 extend dominance into early austral autumn (March/April). The occurrence of CT4 was a bit mixed up - it has a high probability to occur, almost homogenously, at any time of the year. CT17 is specifically an austral spring dominant pattern. In general, CT2, CT5, CT8, CT10, CT12, CT13, CT15, CT18 can be grouped as warm-season CTs.

Table 1 Percentage of variance explained by the retained components
The probability of occurrence of the CTs (Fig. 5) was calculated as the ratio of the number of days clustered under the CT to the total number of days in the study period (i.e. 14,610 days). CT1 is the most occurred cold season CT in the study period, followed by CT9. CT5 similarly, is the most occurred warm-season CT, followed by CT8. CT5 is the austral summer climatology of atmospheric circulation in the study region. CT12 and CT18 are relatively rare CTs. CT1 is close to the climatological mean state of SLP field variability in the study region (Moleteni et al. 1990).

The oblique rotation allows inter-correlation between the component scores, and also a day might have high loadings $(>0.2)$ under more than one retained component so that the classification procedure allows for the grouping of a day under more than one CT, which logically implies the CTs that occurred on the day in question. Since the classified data is continuous, overlapping of the classified variable is physically realistic (Gong and Richman 1995). As a result, the sum of the percentages in Fig. 5 does not add up to $100 \%$. Atmospheric circulation is a continuum and this justifies the relaxation of a rigid grouping (e.g. K-means clustering), which allows a day to be classified under only one CT. CT1, CT4, CT5, and CT8 were found to relatively have a higher probability to occur. Harr and Elsberry (1995) explained such CTs as nearly constant patterns that have slowly varying features. Also, the separability between the classes was satisfactorily large except with the aforementioned CTs designated as the nearly constant patterns.

\subsection{Linkage of wet and dry days in Free State to the circulation types}

The probability of dry days and wet days in each CT was calculated using Eqs. 1 and 2 respectively. The distribution of the probability of dry days in each of the $18 \mathrm{CTs}$, across the 11 stations, can be visualized in Fig. 6 (bottom panel). Recall that CT1, CT6, CT7, CT9, CT11, CT14, and CT16 were categorized as cold season CTs. Figure 6 shows that these CTs have, relatively, higher chances of being associated with dry days in Free State. According to Reason and Mulenga (1999), the reason is that SST anomalies in the southwest Indian Ocean influence the inter-seasonal rainfall variability of South Africa; they linked dry days in South Africa to the cooling of SST at the southwest Indian Ocean-which is a common phenomenon in the cold season CTs. From Fig. 3, for the aforementioned cold season CTs, anti-cyclonic circulation dominates over the southwest Indian Ocean. Anti-cyclonic circulation is normally associated with less convective activity (Harr and Elsberry 1995). CT6 and CT14 have the highest probability of being associated with dry days in Free State. Figure 6 (top panel) also shows that relatively, there is generally a low possibility of 

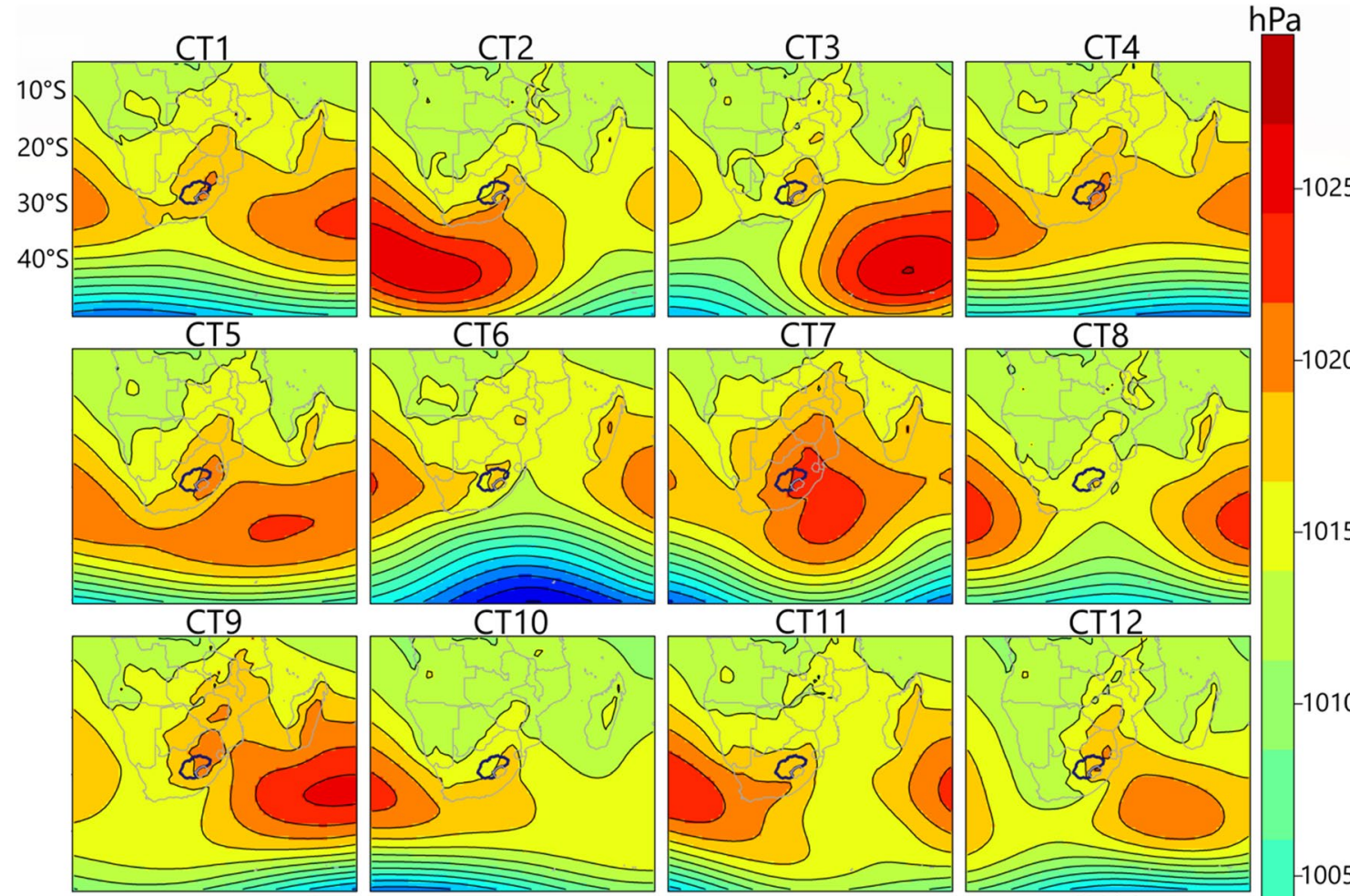

$-1020$
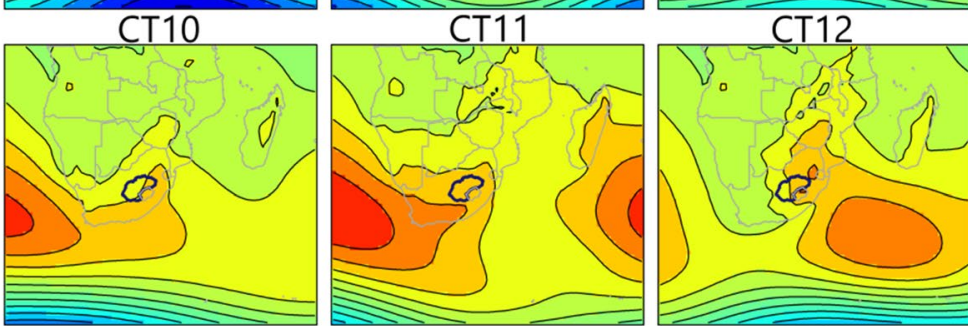

25
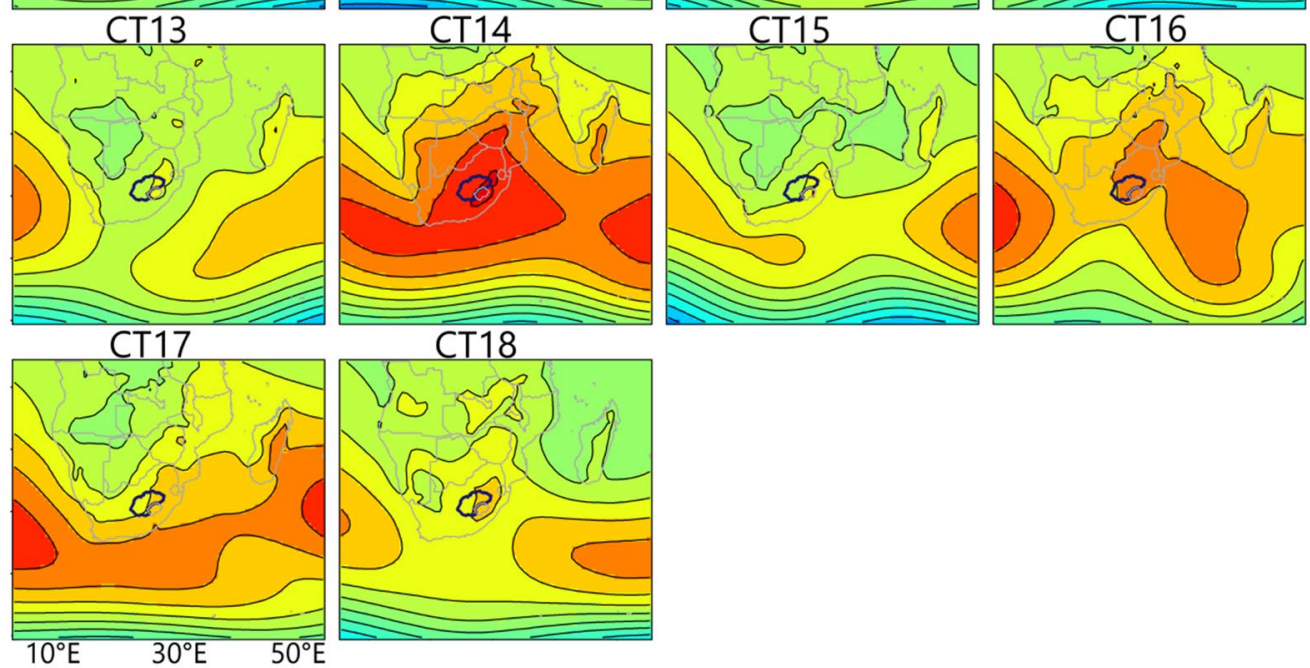

Fig. 3 The circulation types in the study region. The blue polygon shows the location of Free State in the maps. CTs are the mean SLP field for the days clustered under a given class

wet days when either of these dry CTs occurs-supporting the fact they are truly dry synoptic situations in Free State. For each of the 11 stations, CT6 has the highest probability of being associated with dry days.

Figure 8 shows the SLP field; moisture flux and divergence field at $850 \mathrm{hPa}$, during CT6 and CT14. Under CT14 a high-pressure system and associating divergence are evident over Free State and the Greater Agulhas region. This leads to subsidence (rainfall suppression), and reduction of convective activity at the Agulhas current, which is a principal source of moisture to South Africa. Under CT6, the midlatitude cyclone strengthens and tracks further north so that westerly wind is enhanced in the advection of cold drier to Free State. While the synoptic situation of CT6 favors cold fronts to sweep across the southwestern regions of South Africa (Reason and Rouault 2005; Ibebuchi 2021b), here it is shown that the band of westerly rather suppresses rainfall in the Free State. This is because, in addition to the transport of drier air from the Benguela regions, moist southeasterly winds from the southwest Indian Ocean are 
Fig. 4 Monthly relative frequency of occurrence (in percentage) for each of the CTs for the 1979-2018 period

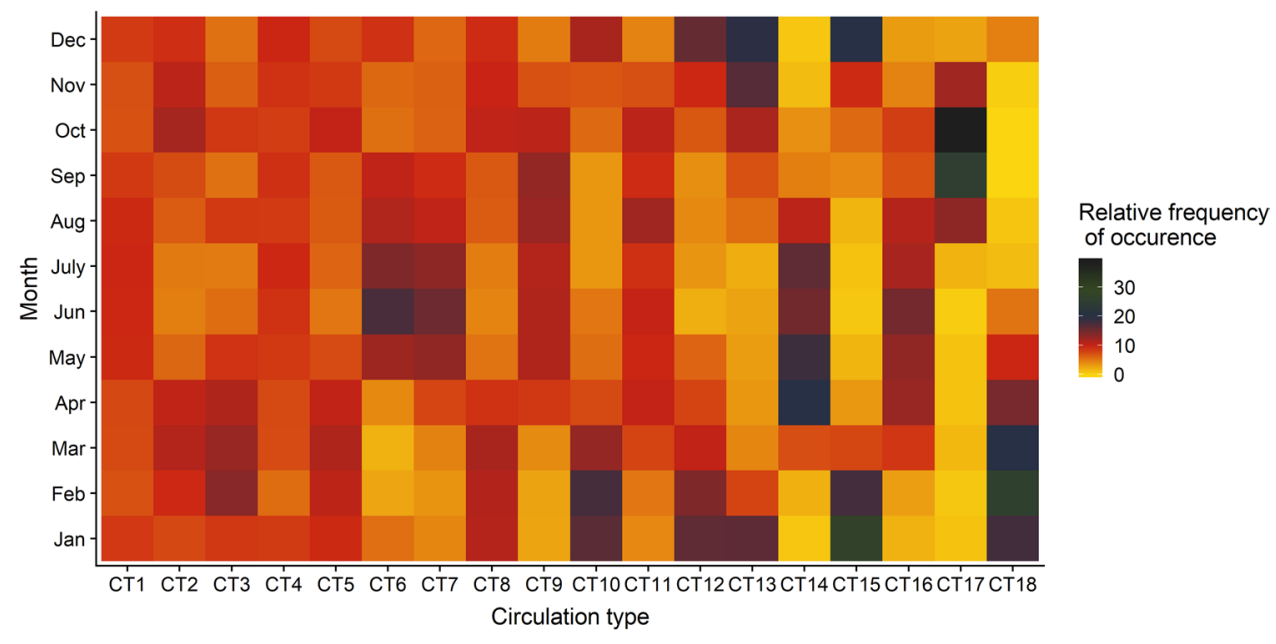

Fig. 5 Probability of occurrence of the CTs for the 1979-2018 period. The values on top of the bars are the number of days clustered under each CT

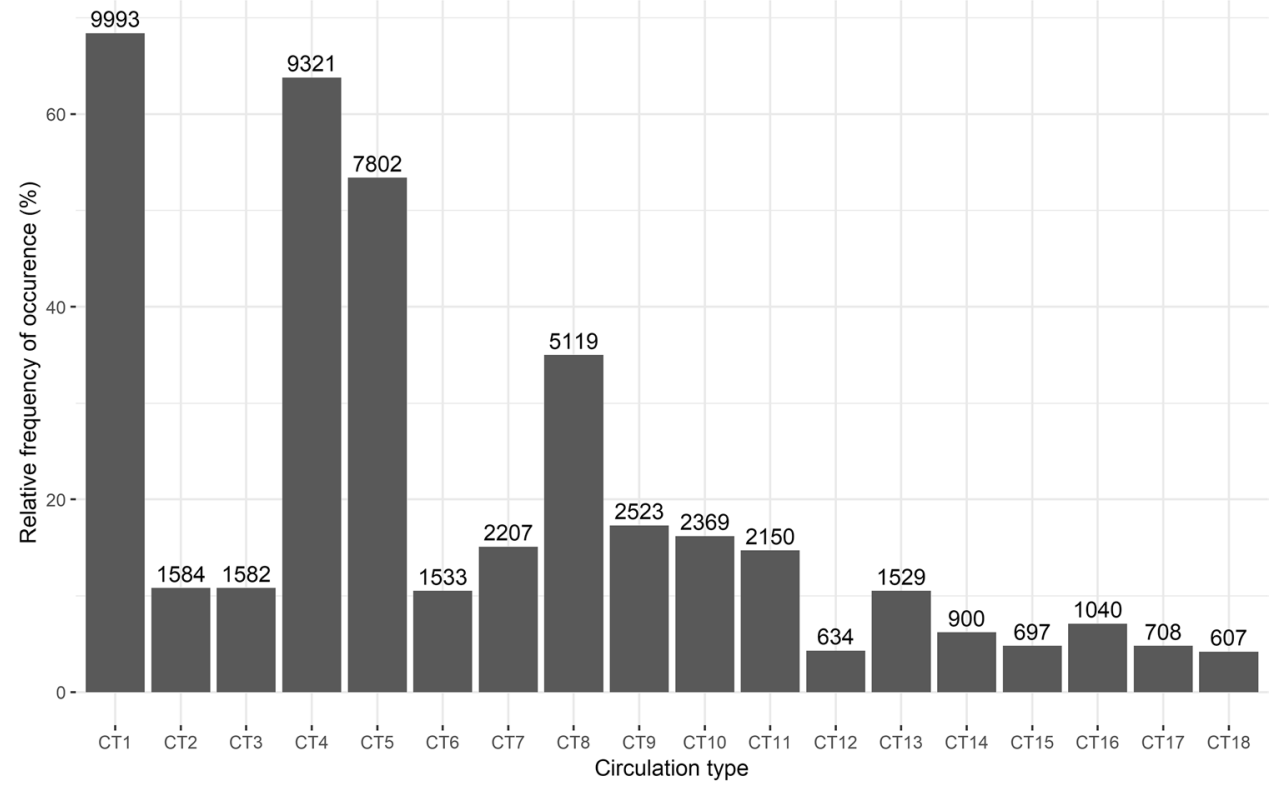

weakened. Moreover, Jury (2015) highlighted that during El Niño events when anomalous rainfall decrease is expected in southern Africa, westerly winds transport cold dry air onto the South Africa plateau. Hence at the synoptic scale, enhanced dryness in Free State can be attributed to largescale subsidence, suppression of convection at the Greater Agulhas region, and advection of cold dry air from the Benguela region by extratropical westerly winds.

From Fig. 6 (bottom panel), for the warm season CTs, i.e. CT2, CT3, CT5, CT8, CT10, CT12, CT13, CT15, and CT18, the probability of dry days in these CTs are generally less, relative to the cold season CTs. Figure 6 (top panel) shows the distribution of the probability of each CT to bring wet days across the 11 stations. For the eleven selected stations in Free State, Fig. 8 shows the regions under the dominant influence of a given $\mathrm{CT}$, based on having the highest probability of bringing wet days (Fig. 7A) and the probability of bringing extreme rainfall (Fig. 7B). An extreme rainfall day for each CT was characterized as the count of days with daily rainfall amount greater than the 99 percentile rainfall value, per station. Figure 6 and Fig. 7 show that CT12 has the highest chances of being associated with widespread extreme rainfall in most regions in Free State. Southwestern regions in Free State are more likely to be influenced by the dynamics of CT15. Some regions are under the influence of CT13. However, the application of the classification scheme to other SLP gridded data sets (e.g. Ibebuchi 2021b) reproduced all the CTs except CT13, suggesting that it might be an artifact of ERA-Interim. Hence more focus will be placed on CT15.

From Fig. 8, at the synoptic scale, extreme rainfall in most regions in Free State under CT12 can be attributed to the strengthening of the South Indian Ocean highpressure. This leads to enhanced low-level advection of 

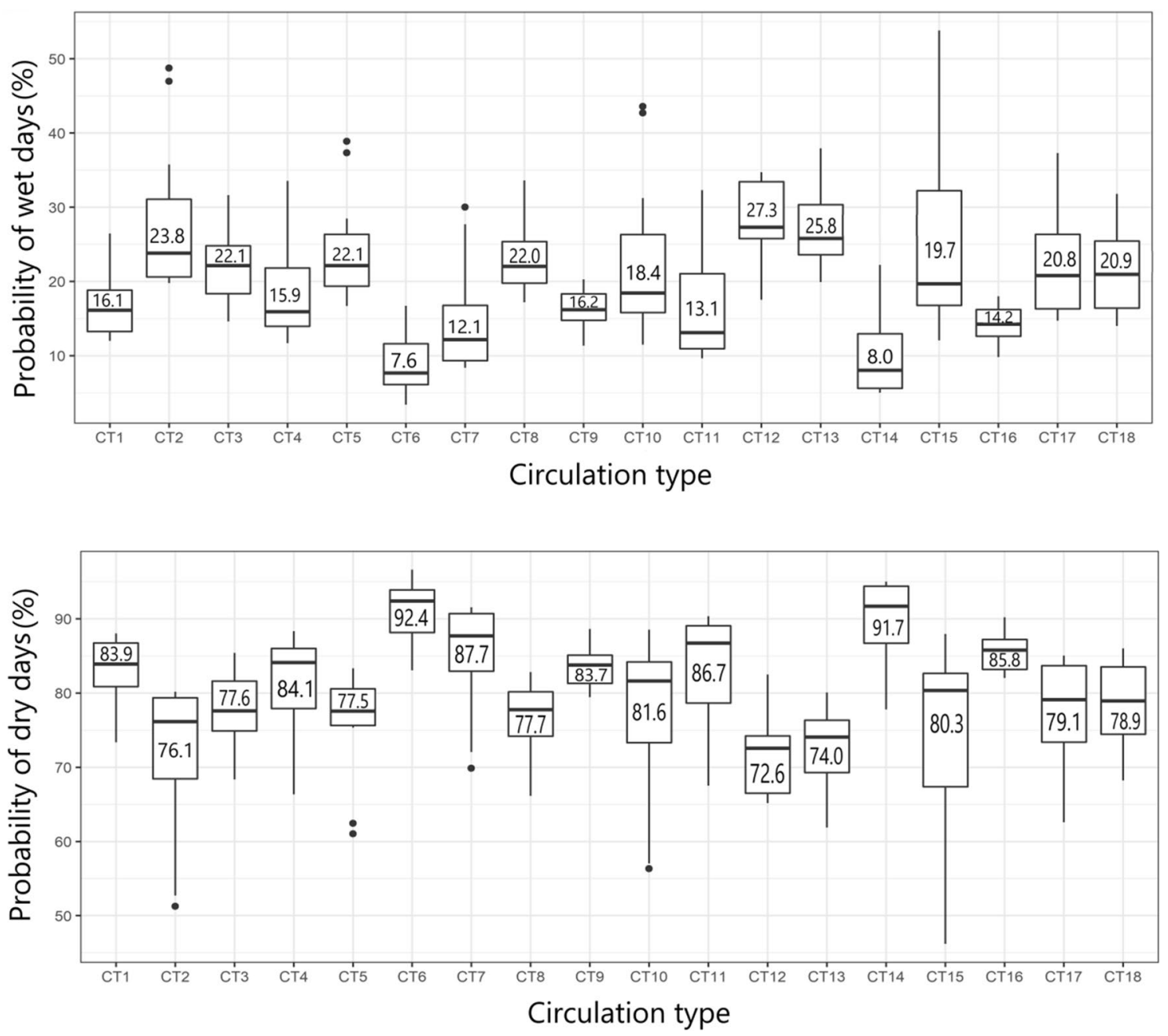

Fig. 6 Distribution of the probability of wet days (top panel) and dry days (bottom panel) under each CT, across the eleven stations in Free State. The number in the box-plot is the median of the probability across the eleven stations. The probabilities were calculated using Eqs. 1 and 2. The distribution ranges from gamma to normal distri-

moisture by the southeast wind. Also, under CT12 the offshore movement of the thermal low into the South Atlantic east Coast and the weakening of the South Atlantic Ocean high-pressure reflect moistening of the western subtropical boundary layer. Thus, more moisture is available to be advected into Free State by westerly winds. On the other hand, CT15 reflects enhanced convergence of moist winds from the Angola warm current and crossequatorial trade wind into the Angola low. The western branch of the South Indian Ocean high-pressure is equally weakened so that fewer southeast winds penetrate Free State compared to CT12. However, the continental tropical low evident in this synoptic situation, coupled with the enhanced cyclonic activity at the Agulhas region, and the enhanced convergence at the Angola low are generally favorable for the enhancement of deep convection at bution, depending on the CT. To estimate the true probabilities, the parameters of the fitted appropriate theoretical distribution was estimated using the Maximum likelihood method, and the median value calculated in each case

preferred regions in Free State. In general, extreme rainfall in Free State can be attributed to enhanced transport of moisture by southeast and southwest winds into the local study region; the formation of continental tropical lows at the western regions of southern African, coupled with enhanced cyclonic activity in the Agulhas region.

From the classification scheme in this paper, the March 1988 incidence in Free State which was accompanied by heavy flood episodes on 10 and 11 March (Walker and Lindesay 1989) can be attributed to the occurrence and persistence of CT12 from 10 March, to 11 March when it also co-occurred with CT15. The average rainfall on $10 \mathrm{March}$ alone for the eleven selected stations in Free State is $45 \mathrm{~mm}$, and $32 \mathrm{~mm}$ on 11 March. Figure 9 shows the SLP, $850 \mathrm{hPa}$ moisture flux, and specific humidity for 10 and 11 March 1988. Similar to the synoptic features of CT12 (c.f. Figs. 3, 

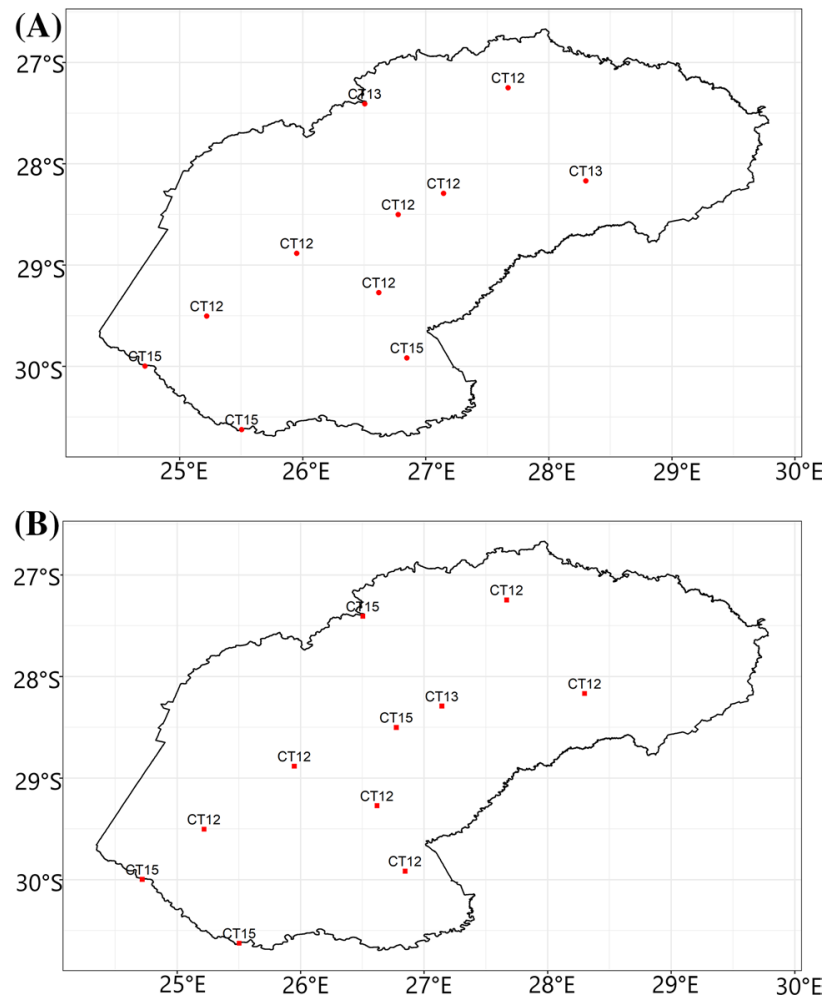

Fig. 7 Analysis of the CT with the highest probability of wet days (A) and extreme rainfall days (B) at each of the selected stations

8), a weaker anticyclonic circulation at the South Atlantic Ocean high-pressure; the offshore movement of thermal low into the South Atlantic east coast; and stronger anticyclonic circulation at the western branch of the South Indian Ocean high-pressure, resulting in enhanced low-level moisture transport by moist southeast and southwest winds into the southern African mainland is evident during these days. Also with the occurrence of CT15 on 11 March, a cyclonic circulation can be seen over Angola so that northwest winds are evident compared to 10 March. Thus the persistence of the synoptic state of CT12 from 10 to 11 March 1988 contributed significantly to the flood incidence.

\section{Discussion}

In this study, the CTs in southern Africa were classified and linked to rainfall variability in Free State, South Africa. The CTs associated with the higher probability of being associated with wet days and dry days in Free State were noted. The mechanisms, in the light of moisture flux and convergence, through which the selected CTs can influence the intensity and spatial variability of rainfall across 11 stations in Free State were equally analyzed.
Using obliquely rotated PCA on the T-mode matrix of the SLP data set (Richman 1981), 18 CTs were classified and each CT was found to be related to the probability of a specific weather event in the local climate. CTs dominant in austral summer and austral late spring - when SST is high at the southwest Indian Ocean-were found to be associated with a higher possibility of bringing wet days to Free State. Austral winter and austral late autumn dominant CTs-when SST is low at the southwest Indian Ocean - were found to be associated with a higher possibility of bringing dry days to Free State. The results are in line with the finding of Reason and Mulenga (1999) that SST anomalies at the southwest Indian Ocean explain to a good extent the inter-seasonal variability of rainfall in South Africa.

The synoptic situation associated with the highest probability of wet days and extreme wet days in Free State is characterized by stronger anti-cyclonic circulation at the South Indian Ocean high-pressure leading to the enhanced low-level transport of moisture from the southwest Indian Ocean by southeast winds. It equally features moistening of the Benguela current due to a weaker state of the South Atlantic Ocean high-pressure (Vigaud et al. 2009). According to Lazenby et al. (2016), a stronger circulation at the South Indian Ocean high-pressure during austral summer correlates with the strengthening of the SICZ and enhanced rainfall in southern Africa. On the other hand, the occurrence of continental tropical lows at the western region of southern Africa, and enhanced cyclonic activity at the Agulhas region were equally found to cause enhanced rainfall in some regions in Free State. This is in agreement with the finding of Walker (1990), that convective activity at the Agulhas current can influence rainfall variability in South Africa. Enhanced (winter) dry conditions in Free State was found to be attributed to large-scale subsidence (Dedekind et al. 2016), suppression of convection at the Greater Agulhas region (Reason 2001), and advection of cold dry air from the Benguela region to Free State, by the extratropical westerly wind (Jury 2015).

\section{Conclusions}

From the classification of CTs in southern Africa and the linkage of the CTs to wet days, heavy wet days, and dry days from eleven rainfall stations in Free State, it was found that wet/dry conditions in Free State are prevalent in warm/cold seasons when convective activity is high/ low in the southwest Indian Ocean. At the synoptic scale, wet days in Free State can be associated with (i) enhanced low-level transport of moisture by strong anticyclonic circulation at the western branch of the South Indian Ocean high-pressure coupled with the moistening of the Benguela 

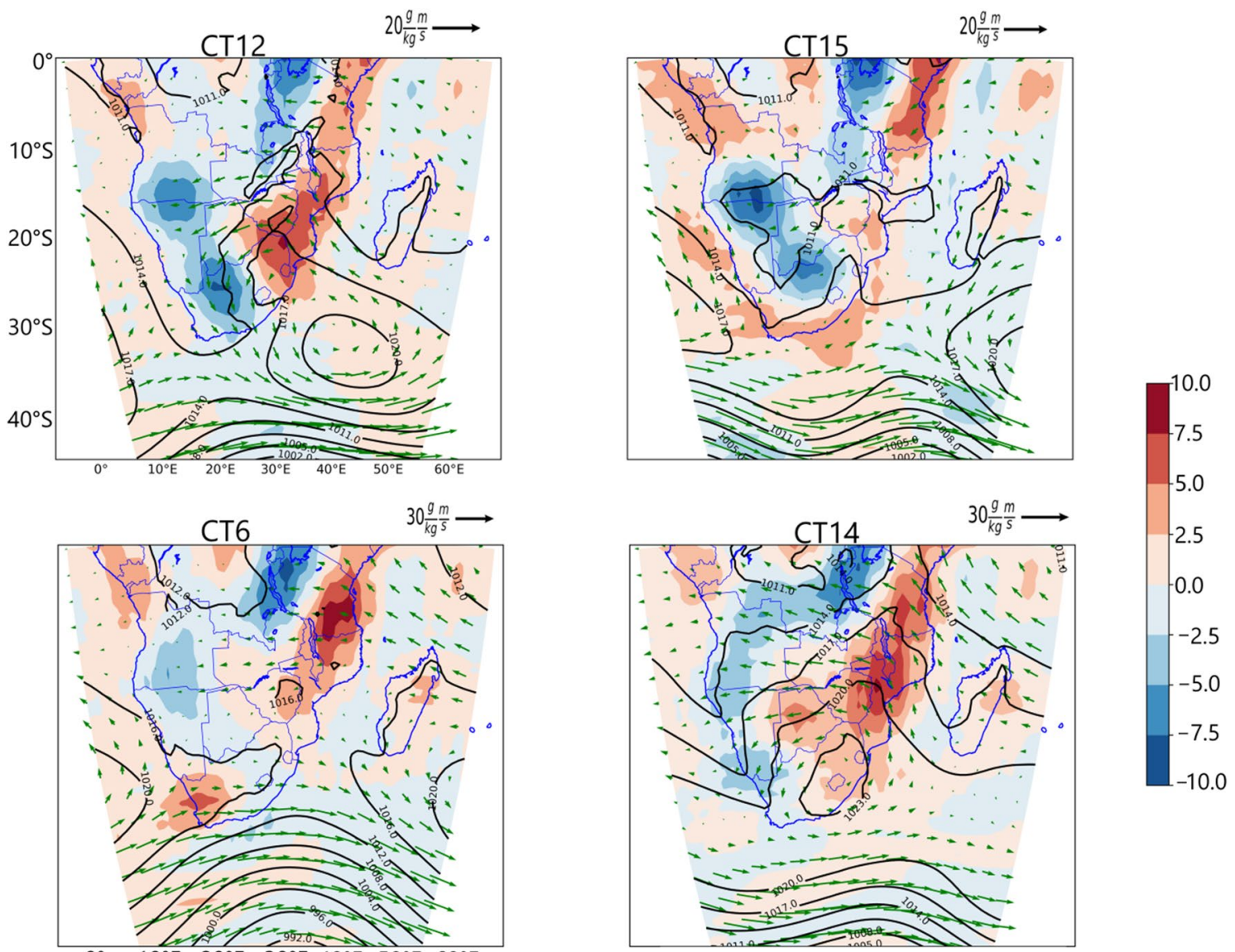

Fig. 8 Physical mechanism associated with the CTs with the highest probability of wet days and dry days in Free State. Color is the composite of the divergence field at $850 \mathrm{hPa}$ with the unit in $10^{6} / \mathrm{s}$,

the green vector is moisture flux at $850 \mathrm{hPa}$ with the unit in $\mathrm{g} / \mathrm{kg} \mathrm{m} / \mathrm{s}$. Vector scale is written on top of the maps
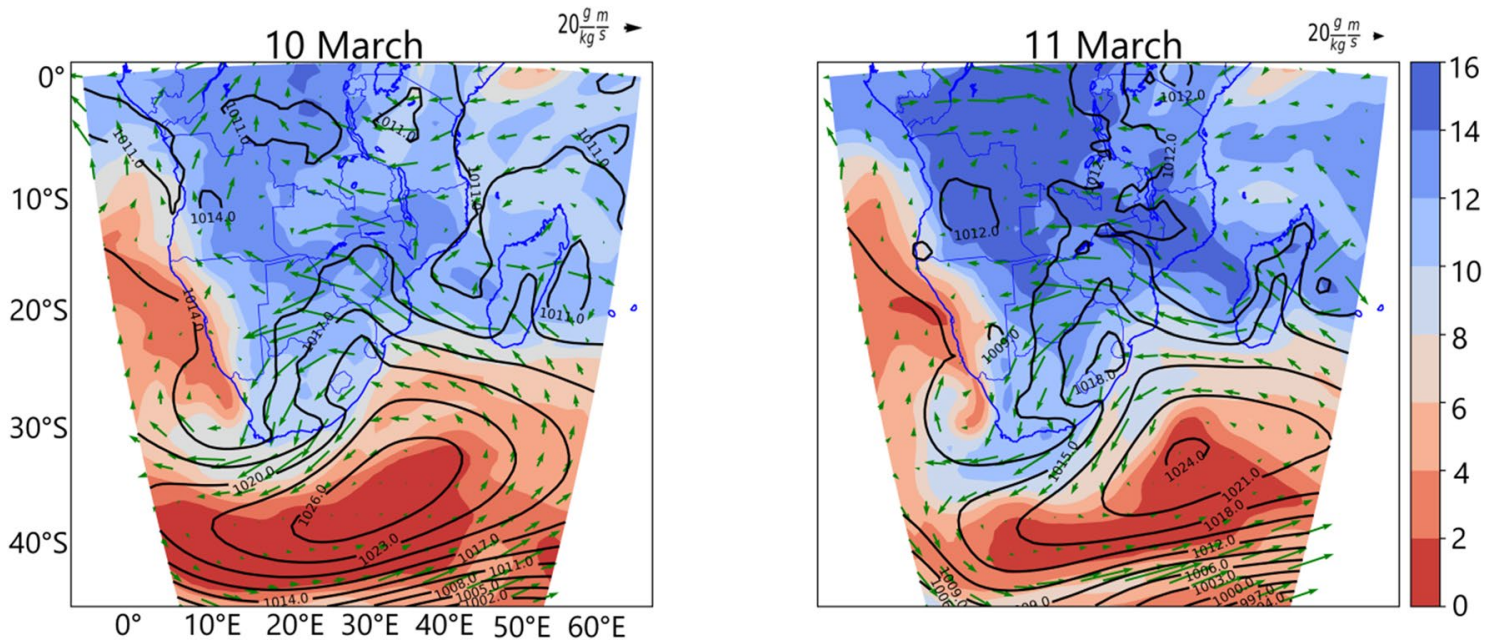

Fig. 9 Composites of SLP, $850 \mathrm{hPa}$ moisture flux, and specific humidity on 10 March and 11 March 1988. Contour is SLP in hPa, the interval is $3 \mathrm{hPa}$. Color is specific humidity in $\mathrm{g} / \mathrm{kg}$. Vector is moisture flux and vector scale is written on the map 
region, (ii) and enhanced convective activity at the Agulhas current coupled with the formation of continental tropical lows at the western regions of southern Africa. On the other hand, dry conditions in Free State can be associated with (i) anticyclonic activity on the landmasses and the Greater Agulhas region, (ii) and transport of cold dry air to Free State by the extratropical westerly winds.

The findings in this study extend the predictability of rainfall in Free State both under the current climate and for studies based on future climate change conditions and thus can be useful to water decision policy-makers and for a local weather agency. An increase in SST is among the signals of global warming; however at the synoptic scale, during austral summer, a weaker (stronger) circulation at South Indian Ocean high-pressure might imply weakening (strengthening) of the hydroclimate of Free State due to diminished (enhanced) advection of moisture by southeast winds. However, a weakening of advection might still be compensated by enhanced moisture uptake at the adjacent oceans, so that extremes in rainfall might still be possible in Free State.

Funding Open Access funding enabled and organized by Projekt DEAL. This research received no specific grant from any funding agency in the public, commercial, or not-for-profit sectors.

\section{Declarations}

Availability of data and material ERA-Interim reanalysis data sets are available at: https://www.ecmwf.int/en/forecasts/datasets/reanalysisdatasets/era-interim and the station rainfall data sets are available at http://www.dwa.gov.za/Hydrology/Verified/hymain.aspx.

Conflict of interest There are no conflicts of interest in this paper.

Open Access This article is licensed under a Creative Commons Attribution 4.0 International License, which permits use, sharing, adaptation, distribution and reproduction in any medium or format, as long as you give appropriate credit to the original author(s) and the source, provide a link to the Creative Commons licence, and indicate if changes were made. The images or other third party material in this article are included in the article's Creative Commons licence, unless indicated otherwise in a credit line to the material. If material is not included in the article's Creative Commons licence and your intended use is not permitted by statutory regulation or exceeds the permitted use, you will need to obtain permission directly from the copyright holder. To view a copy of this licence, visit http://creativecommons.org/licenses/by/4.0/.

\section{References}

Archer E, Landman W, Malherbe J, Tadross M, Pretorius S (2019) South Africa's winter rainfall region drought: a region in transition? Clim Risk Manag. https://doi.org/10.1016/j.crm.2019. 100188
Brisson E, Demuzere M, Kwakernaak B, Van-Lipzig NP (2011) Relations between atmospheric circulation and precipitation in Belgium. Meteorol Atmos Phys 111(1):27-39. https://doi.org/10. 1007/s00703-010-0103-y

Cattell RB (1966) The Scree test for the number of factors. Multivar Behav Res 1(2):245-276. https://doi.org/10.1207/s15327906m br0102_10

Compagnucci RH, Richman MB (2008) Can principal component analysis provide atmospheric circulation or teleconnection patterns? Int J Climatol 28(6):703-726. https://doi.org/10.1002/joc.1574

Cook KH (2000) The South Indian convergence zone and interannual rainfall variability over Southern Africa. J Clim 13(21):37893804. https://doi.org/10.1175/1520-0442(2000)013\%3c3789: TSICZA\%3e2.0.CO;2

Dedekind Z, Engelbrecht FA, Merwe J (2016) Model simulations of rainfall over southern Africa and its eastern escarpment. Water SA 42(1):129. https://doi.org/10.4314/wsa.v42i1.13

Dee DP, Uppala SM, Simmons AJ et al (2011) The ERA-interim reanalysis: configuration and performance of the data assimilation system. Q J R Meteorol Soc 137(656):553-597. https://doi.org/ 10.1002/qj.828

Esteban P, Jones PD, Martin-Vide J, Mases M (2005) Atmospheric circulation patterns related to heavy snow days in Andorra. Pyren Int J Climatol 25(3):319-329. https://doi.org/10.1002/ joc. 1103

Harr AP, Elsberry RL (1995) Large-scale circulation variability over the Tropical Western North Pacific Part 1 spatial patterns and tropical cyclone characteristics. Mon Weather Rev 123(5):12251246. https://doi.org/10.1175/1520-0493(1995)123\%3c1225: LSCVOT\%3e2.0.CO;2

Ibebuchi CC (2021a) On the fuzziness of circulation types derived from the application of obliquely rotated principal component analysis to a T-mode climatic field. Res Sq. https://doi.org/10.21203/rs.3. rs-530514/v1

Ibebuchi CC (2021b) On the relationship between circulation patterns, the southern annular mode, and rainfall variability in Western Cape. Atmosphere 12:753. https://doi.org/10.3390/atmos 12060 753

IPCC (2013) The physical science basis. In: Stocker TF, Qin D, Plattner GK, Tignor M, Allen SK, Boschung J, Nauels A, Xia Y, Bex V, Midgley PM (eds) Contribution of working group I to the fifth assessment report of the intergovernmental panel on climate change. Cambridge University Press, Cambridge, 1535 pp. doi: https://doi.org/10.1017/CBO9781107415324

Jury MR (2015) Passive suppression of South African rainfall by Agulhas current. Earth Interact 9(13):1-14. https://doi.org/10.1175/ EI-D-15-0017.1

Kendall MG (1975) Rank correlation methods. Griffin, London

Kidson JW (1997) The utility of surface and upper air data in synoptic climatological specification of surface climatic variables. Int $\mathrm{J}$ Climatol 17(4):399-414. https://doi.org/10.1002/(SICI)10970088(19970330)17:4\%3c399::AID-JOC108\%3e3.0.CO;2-M

Kuo HL (1965) On the formation and intensification of tropical cyclones through latent heat released by cumulus convection. JAS 22(1):40-63. https://doi.org/10.1175/1520-0469(1965)022\% 3c0040:OFAIOT\%3e2.0.CO;2

Lazenby MJ, Todd MC, Wang Y (2016) Climate model simulation of the South Indian Ocean Convergence Zone: mean state and variability. Clim Res 68(1):59-71. https://doi.org/10.3354/cr01382

Lemus-Canovas M, Lopez-Bustins J, Trapero L, Martin-Vide J (2019) Combining circulation weather types and daily precipitation modeling to derive climatic precipitation regions in the Pyrenees. Atmos Res 220:181-193. https://doi.org/10.1016/j.atmosres.2019. 01.018 
Loriaux JM, Lenderink G, Siebesma P (2017) Large-scale controls on extreme precipitation. J Clim 30(3):955-968. https://doi.org/10. 1175/JCLI-D-16-0381.1

Maheras P, Kolyva-Machera F (1990) Temporal and spatial characteristics of annual precipitation over the Balkans in the twentieth century. Int J Climatol 10(5):495-504. https://doi.org/10.1002/ joc.3370100506

Mann HB (1945) Non-parametric tests against trend. Econometrica 13(3):245-259

Maraun D, Widmann M (2018) Statistical downscaling and bias correction for climate research. Cambridge University Press, Cambridge. https://doi.org/10.1017/9781107588783

Martin-Vide J, Sanchez-Lorenzo A, Lopez-Bustins J, Cordobilla MJ, Garcia-Manuel A, Raso JM (2008) Torrential rainfall in the northeast of the Iberian Peninsula: synoptic patterns and WeMO influence. Adv Sci Res 2(1):99-105. https://doi.org/10.5194/ asr-2-99-2008

Moleteni F, Tibaldi S, Palmer TN (1990) Regimes in the wintertime circulation over northern extratropics. I: observational evidence. Q J R Meteorol Soc 116(49):31-67. https://doi.org/10.1002/qj. 49711649103

Munday C, Washington R (2017) Circulation controls on Southern Africa precipitation in coupled models: the role of the Angola low. J Geophys Res Atmos 122(2):861-877. https://doi.org/10. 1002/2016JD025736

Ninomiya K (2008) Similarities and differences among the South Indian Ocean convergence zone, North American convergence zone, and other subtropical convergence zones simulated using an AGCM. J Meteorol Soc Jpn 86(1):141-165. https://doi.org/ $10.2151 / j m s j .86 .141$

North G, Bell T, Cahalan FR, Moeng FJ (1982) Sampling errors in the estimation of empirical orthogonal functions. Mon Weather Rev 110(7):699-706. https://doi.org/10.1175/1520-0493(1982)110\% 3c0699:SEITEO\%3e2.0.CO;2

Plavcova E, Kysely J, Stepanek P (2013) Links between circulation types and precipitation in Central Europe in the observed data and regional climate model simulations. Int J Climatol 34(9):28852898. https://doi.org/10.1002/joc.3882

Preisendorfer RW, Zwiers FW, Barnett TP (1981) Foundations of principal component selection rules. Scripps Institute of Oceanography, La Jolla, California, SIO Ref. Series 81-4 (NTIS PB); 83-146613

Reason CJC (2001) Evidence of the influence of the Agulhas Current on regional atmospheric circulation patterns. J Clim 14(12):27692778. https://doi.org/10.1175/1520-0442(2001)014\%3c2769: EFTIOT\%3e2.0.CO;2

Reason CJC, Mulenga H (1999) Relationships between South African rainfall and SST anomalies in the southwest Indian Ocean. Int J Climatol 19(15):1651-1673. https://doi.org/10.1002/(SICI)10970088(199912)19:15\%3c1651::AID-JOC439\%3e3.0.CO;2-U

Reason CJC, Rouault M (2005) Links between the Antarctic Oscillation and winter rainfall over western South Africa. Geophys Res Lett. https://doi.org/10.1029/2005GL022419

Reason CJC, Smart S (2015) Tropical Southeast Atlantic warm events and associated rainfall anomalies over Southern Africa. Front Environ Sci 3:24. https://doi.org/10.3389/fenvs.2015.00024
Richman MB (1981) Obliquely rotated principal components: an improved meteorological map typing technique? J Appl Meteorol 20(10):1145-1159. https://doi.org/10.1175/1520-0450(1981) 020\%3c1145:ORPCAI\%3e2.0.CO;2

Richman MB (1986) Rotation of principal components. J Climatol 6(3):293-335. https://doi.org/10.1002/joc.3370060305

Richman MB, Gong X (1999) Relationships between the definition of the hyperplane width to the fidelity of principal component loadings patterns. J Clim 12(6):1557-1576. https://doi.org/10.1175/ 1520-0442(1999)012\%3c1557:RBTDOT\%3e2.0.CO;2

Richman MB, Lamb PJ (1985) Climatic pattern analysis of three and seven-day summer rainfall in the Central United States: some methodological considerations and regionalization. J Clim Appl Meteorol 24(12):1325-1343. https://doi.org/10.1175/15200450(1985)024\%3c1325:CPAOTA\%3e2.0.CO;2

Seibert P, Frank A, Formayer H (2007) Synoptic and regional patterns of heavy precipitation in Austria. Theor Appl Climatol 87(1):139 153. https://doi.org/10.1007/s00704-006-0198-8

Sousa PM, Blamey RC, Reason CJC, Ramos AM, Trigo RM (2018) The 'Day Zero' Cape Town drought and the poleward migration of moisture corridors. Env Res Lett 13:124025. https://doi.org/10. 1088/1748-9326/aaebc7

Sylla MB, Giorgi F, Ruti PM, Calmanti S, Dell'Aquila D (2011) The impact of deep convection on west African summer monsoon climate: a regional climate model sensitivity study. Q J R Meteorol Soc 137(659):1417-1430. https://doi.org/10.1002/qj.853

Tyson PD (1986) Climatic change and variability in Southern Africa. Oxford University Press, Capetown

Vigaud N, Richard Y, Rouault M, Fauchereau N (2009) Moisture transport between the South Atlantic Ocean and Southern Africa: relationships with summer rainfall and associated dynamics. Clim Dyn 32(1):113-123. https://doi.org/10.1007/s00382-008-0377-7

Walker ND (1990) Links between South African summer rainfall and temperature variability of the Agulhas and Benguela Current systems. J Geophys Res Oceans 95(C3):3297-3319. https://doi.org/ 10.1029/JC095iC03p03297

Walker ND, Lindesay JA (1989) Preliminary observations of oceanic influences on the February-March 1988 floods in Central South Africa. S Afr J Sci 85(3):164-169. https://doi.org/10.1052/AJA00 382353_6549

Wilks DS (2006) Statistical methods in the atmospheric sciences, 2nd edn. Int Geophys Ser. ISBN 13: 978-0-12-751966-1

Zuma-Netshiukhwi G, Stigter K, Walker S (2013) Use of traditional weather/climate knowledge by farmers in the south-western free state of South Africa: agrometeorological learning by scientists. Atmosphere 4(4):383-410. https://doi.org/10.3390/atmos4040383

Publisher's Note Springer Nature remains neutral with regard to jurisdictional claims in published maps and institutional affiliations. 